\title{
THE EFFECTS OF ORGANIZATIONAL JUSTICE PERCEPTIONS ON CYBER-LOAFING BEHAVIORS: A RESEARCH ON HEALTH WORKERS
}

\section{DOI: 10.17261/Pressacademia.2017.717 \\ RJBM- V.4-ISS.3-2017(16)-p.400-409}

\section{Ferda Alper $\mathbf{A y}^{1}$, Gulbahtiyar Demirel ${ }^{2}$, Nuriye Erbas ${ }^{3}$}

${ }^{1}$ Cumhuriyet Üniversitesi Sağlık Bilimleri Fakültesi, Sağlık Yönetimi Bölümü, Sivas, Türkiye. ferdaalperay@hotmail.com

${ }^{2}$ Cumhuriyet Üniversitesi Sağılık Bilimleri Fakültesi, Ebelik Bölümü, Sivas, Türkiye. gulbahtiyar_doganer@hotmail.com

${ }^{3}$ Cumhuriyet Üniversitesi Sağlık Bilimleri Fakültesi, Hemşirelik Bölümü, Sivas, Türkiye. nerbas2006@gmail.com

To cite this document

Ay, F.A., G. Demirel and N. Erbas, (2017). The effects of organizational justice perceptions on cyber-loafing behaviours: a research on heath workers. Research Journal of Business and Management (RJBM), V.4, p.400-409.

Permemant link to this document: http://doi.org/10.17261/Pressacademia.2017.717

Copyright: Published by PressAcademia and limited licenced re-use rights only.

\section{ABSTRACT}

Purpose- The aim of this study is to determine the effects of organizational justice perception on cyber-loafing behaviors.

Method - Data were collected (233) from health care workers who agreed to participate in the study using the questionnaire method. These 233 health workers are working in Departments of Obstetrics and Gynecology (Cumhuriyet University Health Services Research and Implementation Hospital, Sivas Numune Hospital) and Family Health Centers in the city center of Sivas. The data were analyzed by SPSS 22.0 program with percentile distribution, Pearson correlation and multiple regression analysis.

Findings- In the study was determined the negative effect of the operational justice dimension on insignificant cyber-loafing. Moreover, it has been determined that the dimension of interactionel justice has a positive effect on insignificant cyber-loafing behavior.

Conclusion- Positive or negative perception of organizational justice does not cause an increase or decrease in important cyber-loafing behaviors.

Keywords: Operational justice, interactionel justice organizational justice, cyber-loafing, health workers

JEL Codes: M10, M12, M19

ÖRGÜTSEL ADALETIN SANAL KAYTARMA ÜZERINDEKi ETKISI: SAĞLIK ÇALIŞANLARINA YÖNELIK BIR ARAŞTIRMA

\section{ÖZET}

Amaç- Bu çalışmanın amacı, örgütsel adalet algısının sanal kaytarma davranışları üzerine etkilerini belirleyebilmektir.

Yöntem - Araştırmaya anket yöntemiyle katılmayı kabul eden sağlık çalışanlarından veriler toplandı (233). Bu 233 sağlık çalışanı, Sivas şehir merkezindeki Kadın Sağlığı ve Hastalıkları Anabilim Dalı (Sivas Numune Hastanesi Cumhuriyet Üniversitesi Sağlık Hizmetleri Araştırma ve Uygulama Hastanesi) ve Aile Sağlığı Merkezlerinde görev yapmaktadır. Veriler SPSS 22.0 programı ile yüzdelik dağılım, Pearson korelasyon ve çoklu regresyon analizi ile değerlendirilmiştir.

Bulgular- Çalışmada, işlemsel adalet boyutunun önemsiz sanal kaytarma üzerinde negatif etkisi saptanmıştır. Ayrıca etkileşimsel adalet boyutunun önemsiz sanal kaytarma davranışı üzerinde pozitif etkisi olduğu saptanmıştır.

Sonuç- Örgütsel adaleti olumlu veya olumsuz olarak algılama, önemli sanal kaytarma davranışlarında bir artışa veya azalmaya neden olmaz.

Anahtar Kelimeler: İşlemsel adalet, etkileşimsel adalet, örgütsel adalet, sanal kaytarma, sağlık çalışanları.

JEL Kodları: M10, M12, M19 


\section{GiRiş}

Günümüzde işyerinde internet kullanımı, iletişim uygulamalarına önemli kolaylıklar getirmektedir. Bu anlamda internet bağlantısı, çalışanların birbirleri arasındaki iletişimi kolaylaştırmakla beraber, iş yükü açısından da gereksiz işlemlerin azaltılmasına veya ortadan kaldırılmasına imkan vermektedir (Yıldız ve ark., 2015). Türkiye'de 2016 yılı verilerine göre, internet kullanan bireylerin oranı \%61.2'ye yükselmiştir ve genel internet kullanım sıklığı açısından kullanıcıların \%94.9'u düzenli internet kullanıcısıdır. Önceki yıllara göre internet kullanım oranı ve internetin iş ortamındaki kişisel kullanım oranı hızla artmaktadır (TÜiK, 2016).

Kullanımı hızla artan internet ve bilgisayar suistimallere açık bir mecradır (Yıldız ve ark., 2015). Sanal kaytarma iş ortamında bilişim teknolojisi kullanımının suistimal edilmesine bir örnek olup (Ahmadi ve ark., 2011), genel olarak iş amaçlı kullanım için sunulmuş olan bilgisayar ve internet sistemlerinin kişisel amaçlar için kullanılması anlamına gelmektedir (Lim, 2002). Yaşanan teknolojik gelişmeler dikkate alındığında, sanal kaytarma sadece örgütün internet erişim olanakları ile değil, hem örgütsel hem de bireysel internet erişimi sağlayan tüm araçlarla yapılan kaytarma davranışlarını kapsamaktadır (Kaplan ve Öğüt, 2012). Ortam iyi yönetilmediği takdirde, internet çalışanların iş saatleri içerisinde kendi amaçları doğrultusunda kullandığı ve ciddi zamanların harcandığı bir araç haline gelmektedir (Whitty ve Carr, 2006; Wheatherbee, 2010; Kaplan ve Çetinkaya, 2014; Örücü ve Yıldız, 2014). Böylece işletme içerisinde yapılması gereken işler, kişisel amaçlı internet kullanımı nedeniyle yapılmamakta ve iş dışı saatlerde online bağlanma yoluyla tamamlanmaya çalışılmaktadır (Richardson ve Benbunan-Fich, 2011). Bu durum ise, kişinin iş hayatının yanında, aile yaşantısına da olumsuz anlamda etki edebilmektedir (Eivazi, 2011). Sanal kaytarma, şirket kaynaklarının etkin bir şekilde kullanılabilmesini engellemekte, üretkenlik kaybı yaratmakta ve işletmeleri yasal yükümlülükler altına bile sokabilmektedir. Bu nedenle, günümüzde sanal kaytarma dikkat edilmesi gereken önemli bir husus olmuştur (Zoghbi-Manrique-de-Lara ve Melián-González, 2009; Wheatherbee, 2010).

Çalışanları sanal kaytarmaya sürükleyen süreçlerin başında örgütsel adalet algısı gelmektedir. Örgütsel adalet algısı örgüt içerisindeki kazanımların hangi işlemler (procedures) dâhilinde belirlendiği, hangi ölçütler çerçevesinde dağıtıldığı ve dağıtımda hakkaniyet gösterilip gösterilmediği ile ilgilidir (Yıldız ve ark., 2015). Örgütsel adaleti çalışanlar, işverenleri ile ilişkilerini tanımlamak için kullanmaktadırlar. Bu adalet algılaması bireyin kafasında yer almaktadır. Sosyal ve kişilerarası adaleti açıklayan örgütsel adalet, örgütlerdeki davranışı anlamak için başvurulabilir (Cropanzano ve Greenberg, 1997). Çalışanlar, örgütteki kazanımların adaletsiz bir şekilde dağıtıldığını gördüklerinde bu adaletsizliği etkisizleştirmek için sanal kaytarma yoluna gidebilmektedirler. Bu şekilde işletmelerine verecekleri maliyet kayıpları ile kendi tepkilerini göstermektedirler (Forret ve Love, 2008; Syaebani ve Sobri, 2011). Örgütsel adalet; dağıtım adaleti, işlemsel adalet ve etkileşim adaleti olmak üzere üç boyutta ele alınmaktadır (Greenberg, 1990). Lim araştırmasında (2002) örgütsel adalet boyutları (dağıtım, işlemsel ve etkileşimsel) ile sanal kaytarma arasında negatif ilişkiler saptamıştır. Başka bir ifadeyle örgütsel adaletsizlik sanal kaytarmaya neden olabilmektedir.

Hastanelerin Doğum ve Kadın Hastalıkları ile ilgili birimlerinde çalışan sağıık personeli için bir kadının, bir bebeğin mortalitesi ve morbiditesini önlemek için saniyelerin önemi vardır. Doğum ve Kadın Hastalıkları alanı kadınlar için olduğu kadar sağlık çalışanları içinde risklidir. Zaman kaybına tahammülü olmayan, hata götürmeyen bir alandır. Doğum ve Kadın Hastalıkları ile ilgili alandaki sağlık çalışanları, adli ve idari olarak haklarında en çok dava açılan, en çok soruşturma yiyen, en çok şikayet edilen gruplardan biridir. Bu çalışmada, örgütsel adalet algısının azalmasının, çalışanların sanal kaytarma faaliyetleri üzerine bir etkisi olup olmadığı araştırılmıştır. Özellikle sağlık personelinin işyerinde etkin ve verimli çalışması gerektiği düşünüldüğünde, sanal kaytarmanın yol açtığı önemli verimlilik kayıpları ve bu alanda yapılan araştırmaların sınırlılı̆ı araştırmanın önemini daha da ön plana çıkarmaktadır.

\section{YÖNTEM}

Bu bölümde araştırmanın yöntemi; amacı, hipotezleri, tipi, evren ve örneklemi, veri toplama araçları, verilerin toplanması ve analizi hakkında ayrıntılı yer verilmiştir.

Bu çalışmanın amacı, sağlık çalışanlarının sanal kaytarma davranışlarının örgütsel adaletten ne derece etkilendiğini belirlemektir.

\section{Araştırmanın Hipotezleri}

H1: Örgütsel adalet önemli sanal kaytarma üzerinde negatif yönde bir etkiye sahiptir.

H1a: Dağıtımsal adalet önemli sanal kaytarma üzerinde negatif yönde bir etkiye sahiptir.

H1b: İşlemsel adalet önemli sanal kaytarma üzerinde negatif yönde bir etkiye sahiptir.

H1c: Etkileşimsel adalet önemli sanal kaytarma üzerinde negatif yönde bir etkiye sahiptir. H2: Örgütsel adalet önemsiz sanal kaytarma üzerinde negatif yönde bir etkiye sahiptir.

H2a: Dağıtımsal adalet önemsiz sanal kaytarma üzerinde negatif yönde bir etkiye sahiptir.

$\mathrm{H} 2 \mathrm{~b}$ : İşlemsel adalet önemsiz sanal kaytarma üzerinde negatif yönde bir etkiye sahiptir.

$\mathrm{H} 2 \mathrm{c}$ : Etkileşimsel adalet önemsiz sanal kaytarma üzerinde negatif yönde bir etkiye sahiptir. 
H3: Örgütsel adalet sanal kaytarma üzerinde negatif yönde bir etkiye sahiptir.

Araştırmanın Tipi - Araştırma, tanımlayıcı araştırma türündedir.

Araştırmanın Evren ve Örneklemi - Araştırmanın evrenini 26.11.2015/25.02.2016 tarihlerinde Sivas ili merkezindeki hastanelerin Doğum ve Kadın Hastalıkları ile ilgili birimlerinde çalışan (Cumhuriyet Üniversitesi Sağlık Hizmetleri Araştırma ve Uygulama Hastanesi (30 kişi), Sivas Numune Hastanesi (120 kişi) ve Aile Sağlığı Merkezlerinde (Alibaba, Aydoğan, Çarşıbaşı vb. (450 kişi)) sağlık personeli oluşturmuştur. Araştırmanın örneklemi ise 26.11.2015/25.02.2016 tarihlerinde Sivas ili merkezindeki Doğum ve Kadın Hastalıkları ile ilgili hastanelerin (Cumhuriyet Üniversitesi Sağlık Hizmetleri Araştırma ve Uygulama Hastanesi, Sivas Numune Hastanesi) bölümleri ve Aile Sağlığı Merkezlerinde çalışan, çalışmaya katılmaya kabul eden 233 sağlık çalışanı oluşturmuştur.

Araştırmanın Uygulanması - Verilerin Toplanması - Araştırmanın verileri araştırmacılar tarafından literatür bilgisi doğrultusunda oluşturulan demografik bilgiler ile internet kullanımının değerlendirildiği anket formu, sanal kaytarma ölçeği ve örgütsel adalet algısı ölçeği ile toplanmıştır. Araştırmanın yapılabilmesi için Cumhuriyet Üniversitesi Girişimsel Olmayan Klinik Araştırmalar Etik Kurulu'ndan (No: 2015-10/12) ve ilgili kurumlardan izin alınmıştır. Veriler, araştırmacılar tarafından 26.11.2015/25.02.2016 tarihleri arasında gönüllü olarak çalışmaya katılmayı kabul eden sağlık personeline yüz yüze görüşme tekniği ile anket uygulanarak toplanmıştır.

Sosyo-Demografik Veriler: Bu bölümde yaşı, cinsiyeti, mesleği, eğitim düzeyi vb. 7 soru yer almaktadır. İnternet Kullanımı ile ilggili Değişkenleri İnceleyen Veriler: Bu bölümde ise kaç yıldır internet kullandığı, işyerindeki odasında kullandığı internet bağlantısını daha çok hangi kaynaktan sağladığı, kendi internet kullanma becerilerini nasıl değerlendirdiği gibi 11 soru yer almaktadır.

Sanal Kaytarma Ölçeği: Ölçek, Lim (2002) tarafından ve daha sonra Blanchard ve Henle (2008) tarafından geliştirilmiştir. Önemli ve önemsiz sanal kaytarma faaliyetlerinin varlığına ilişkin algıları ölçmektedir. Blanchart ve Henle'nin (2008) çalışmasında, önemsiz sanal kaytarma davranışları (9 madde) ve ciddi sanal kaytarma davranışları (8 madde) olmak üzere 2 faktör ortaya çıktığı görülmüştür. Bu çalışmada Lim'in (2002), Blanchard ve Henle'nin (2008), Özkalp vd. (2012) çalışmalarından yararlanarak Yıldız ve arkadaşlarının (2015) uyarladıkları ve geçerliliğini yaptıkları ölçekten yararlanılmıştır. Sanal kaytarma davranışlarını ölçmek için beşli likert (1=hiçbir zaman, 5=her zaman) tipi 14 sorudan oluşmaktadır. 1-8 numaralı sorular önemli sanal kaytarma faaliyetlerini, 9-14 numaralı sorular ise önemsiz sanal kaytarma faaliyetlerini ifade etmektedir. Ölçeğin Cronbach $\alpha$ değerleri 0,885 'dir. Araştırmamızda ise Cronbach alfa güvenilirlik katsayısı sanal kaytarma ölçeği için 0,849 olarak saptanmıştır $(<0,70)$.

Örgütsel Adalet Algısı Ölçeği: Çalışanların örgütsel adalet algılarını ölçmek için Niehoff ve Moorman'ın (1993) tarafından geliştirilmiş olan ölçek (22 madde), Yıldız ve arkadaşları (2015) tarafından uyarlanmış ve geçerliliği yapılmıştır (18 madde). 15 numaralı sorular dağıtımsal adalet algısını, 6-9 numaralı sorular işlemsel adalet algısını, 10-18 numaralı sorular ise etkileşimsel adalet algısını ifade etmektedir. Ölçek 5 'li likert tipi olup yapısı 1=kesinlikle katılmıyorum, 2=katılmıyorum, 3=ne katılıyorum ne de katılmıyorum, 4=katılıyorum, 5=kesinlikle katılıyorum şeklinde düzenlenmiştir. Ölçeğin Cronbach $\alpha$ değeri 0,926 'dır. Araştırmamızda ise Cronbach alfa güvenilirlik katsayısı örgütsel adalet ölçeği için 0,910 olarak saptanmıştır $(<0,70)$.

Verilerin Değerlendirilmesi - Elde edilen veriler SPSS 22.0 programına yüklenerek verilerin değerlendirilmesinde sayı, yüzdelik dağılım, sanal kaytarma ve örgütsel adalet arasındaki ilişkiler için Pearson korelasyon analizi, örgütsel adaletin sanal kaytarma üzerindeki etkisi için çoklu regresyon analizi kullanılmıştır. İstatistiksel anlamlılık düzeyi p<0.05 olarak kabul edilmiştir.

\section{BULGULAR}

Bu bölümde sağılk çalışanlarının sanal kaytarma davranışlarının örgütsel adaletten ne derece etkilendiği ve aralarındaki ilişki SPSS programı ile belirlenmiştir. Bu bölümde elde edilen analizlerin sonuçlar yer almaktadır.

Araştırmaya katılan toplam 233 sağlık çalışanı sosyo-demografik özelliklerine göre dağılımı Tablo 1'de verilmiştir. Buna göre katılımcıların \%50.2'sinin 29-38 yaş grubunda olduğu, \%80.7'sinin kadın, \%39.9'unun lisans mezunu olduğu, \%44.6'sının ebelerden oluştuğu, \%95.7'sinin pozisyonunun memur olduğu, \%36.5'inin pozisyonda çalışma süresinin 11-15 yıl arası olduğu, \%43.3'ünün kurumda çalışma süresinin 1-5 yıl arasında olduğu saptanmıştır. 
Tablo 1: Sağlık Çalışanlarının Sosyo-Demografik Özelliklerine Göre Dağııımı

\begin{tabular}{|c|c|c|c|c|c|}
\hline & Frekans & Yüzde & & Frekans & Yüzde \\
\hline $\begin{array}{l}\text { Yaş } \\
19-28 \\
29-38 \\
39-48 \\
49 \text { ve üzeri }\end{array}$ & $\begin{array}{r}71 \\
117 \\
34 \\
11\end{array}$ & $\begin{array}{r}30.5 \\
50.2 \\
14.6 \\
4.7\end{array}$ & $\begin{array}{l}\text { Meslek } \\
\text { Doktor } \\
\text { Hemşire } \\
\text { Ebe } \\
\text { Sağlık memuru } \\
\text { Laborant } \\
\text { Sağlık teknisyeni/teknikeri }\end{array}$ & $\begin{array}{r}33 \\
81 \\
104 \\
2 \\
5 \\
8\end{array}$ & $\begin{array}{r}14.2 \\
34.8 \\
44.6 \\
0.9 \\
2.1 \\
3.4\end{array}$ \\
\hline $\begin{array}{l}\text { Cinsiyet } \\
\text { Kadın } \\
\text { Erkek }\end{array}$ & $\begin{array}{r}188 \\
45\end{array}$ & $\begin{array}{l}80.7 \\
19.3\end{array}$ & $\begin{array}{l}\text { Pozisyonda Çalışma Süresi } \\
1-5 \text { yıl arası } \\
6-10 \text { yıl arası } \\
11-15 \text { yıl arası } \\
16 \text { yıl ve üzeri }\end{array}$ & $\begin{array}{l}36 \\
83 \\
85 \\
29\end{array}$ & $\begin{array}{l}15.5 \\
35.6 \\
36.5 \\
12.4\end{array}$ \\
\hline $\begin{array}{l}\text { Eğitim Durumu } \\
\text { Lise } \\
\text { Önlisans } \\
\text { Lisans }\end{array}$ & $\begin{array}{l}75 \\
65 \\
93\end{array}$ & $\begin{array}{l}32.2 \\
27.9 \\
39.9\end{array}$ & $\begin{array}{l}\text { Kurumda Çalışma süresi } \\
1-5 \text { yıl arası } \\
6-10 \text { yıl arası } \\
11-15 \text { yıl arası } \\
16 \text { yıl ve üzeri }\end{array}$ & $\begin{array}{r}101 \\
100 \\
23 \\
9\end{array}$ & $\begin{array}{r}43.3 \\
42.9 \\
9.9 \\
3.9\end{array}$ \\
\hline $\begin{array}{c}\text { Meslek Pozisyonu } \\
\text { Memur } \\
\text { Yönetici }\end{array}$ & $\begin{array}{r}223 \\
10\end{array}$ & $\begin{array}{r}95.7 \\
4.3\end{array}$ & & & \\
\hline Toplam & 233 & 100.0 & Toplam & 233 & 100.0 \\
\hline
\end{tabular}

Tablo 2: Sağlık Çalışanlarının İnternet Kullanım Durumlarının Dağılımı (n:233)

\begin{tabular}{|c|c|c|c|}
\hline İnternet Kullanım Durumları & & $\mathbf{n}$ & $\%$ \\
\hline \multirow[t]{3}{*}{ İnternet kullanım süresi } & $1-5 \mathrm{yll}$ & 42 & 18.0 \\
\hline & $6-10 \mathrm{yıl}$ & 109 & 46.8 \\
\hline & 10 yıldan fazla & 82 & 35.2 \\
\hline \multirow[t]{2}{*}{ Daha çok kullandığı internet bağlantı kaynağı } & Kurum & 98 & 42.1 \\
\hline & Özel hat & 135 & 57.9 \\
\hline \multirow[t]{3}{*}{ İnternet kullanma becerisi } & Başlangıç & 11 & 4.7 \\
\hline & Orta & 150 & 64.4 \\
\hline & illeri & 72 & 30.9 \\
\hline \multirow[t]{3}{*}{ İnternet kullanım sıklığı } & Hergün & 174 & 74.7 \\
\hline & Haftada & 8 & 3.4 \\
\hline & Birkaç gün & 51 & 21.9 \\
\hline \multirow[t]{2}{*}{ İnternette geçirilen günlük saat } & Bir saatten az & 89 & 38.2 \\
\hline & Bir saatten fazla & 144 & 61.8 \\
\hline \multirow[t]{2}{*}{ İnternete kesintisiz bağlı kalma süresi } & Bir saatten az & 137 & 58.8 \\
\hline & Bir saatten fazla & 96 & 41.2 \\
\hline \multirow[t]{2}{*}{ Facebook, twitter gibi sosyal paylaşım sitelerine üyelik } & Evet & 205 & 88.0 \\
\hline & Hayır & 28 & 12.0 \\
\hline Sosyal medya üzerinden çeşitli paylaşımlarda bulunma & Evet & 195 & 83.7 \\
\hline
\end{tabular}




\begin{tabular}{|l|l|r|r|}
\hline video, mesaj vb.) & Hayır & 38 & 16.3 \\
\hline Herhangi bir e-posta grubuna üye olma & & 177 & 76.0 \\
\cline { 2 - 4 } & Hayır & 56 & 24.0 \\
\hline $\begin{array}{l}\text { İnternete bağlanma gerekçesinden uzaklaşarak (bilerek ya da } \\
\text { bilmeyerek) internette farklı konularla ilgilenme }\end{array}$ & Evet & 44 & 18.9 \\
\cline { 2 - 4 } & Hayır & 95 & 40.8 \\
\cline { 2 - 4 } & Bazen & 94 & 40.3 \\
\hline $\begin{array}{l}\text { Mesai saatleri içerisinde internet üzerinde işiniz ile ilgisi } \\
\text { olmayan bir uğraş içerisinde olmak kabul edilebilir bir durum }\end{array}$ & Evet & 26 & 11.2 \\
\cline { 2 - 4 } & Hayır & 81 & 34.8 \\
\cline { 2 - 4 } & Kısmen & 126 & 54.1 \\
\hline
\end{tabular}

Tablo 2'de araştırmaya katılan sağlık çalışanlarının 6-10 yıl arasında internet kullandıkları (\%46.8), işyerinde odalarında kullandıkları internet kaynağını daha çok özel hatlarından sağladıkları (\%57.9), kendi internet kullanım becerilerini orta düzeyde buldukları (\%64.4), her gün interneti kullandıkları (\%74.7), zamanlarının günde bir saatten fazlasını internette geçirdikleri (\%61.8), internete bir saatten az kesintisiz bağlı kaldıkları (\%58.8), facebook, twitter gibi sosyal paylaşım sitelerine üye olanların büyük çoğunlukta olduğu (\%88), sosyal medya üzerinden çeşitli paylaşımlarda bulundukları (\%83.7), herhangi bir e-posta grubuna dahil oldukları (\%76), internete bağlanma gerekçelerinden uzaklaşarak internette farklı konularla ilgilenmedikleri (\%40.8), (ancak "bazen" olarak belirtenlerin oranı (40.3) da oldukça yüksektir), mesai saatleri içerisinde işle ilgisi olmayan bir uğraş içerisinde olmanın kısmen kabul edilebilir bir durum olduğunu (\%54.1) belirttikleri saptanmıştır.

Tablo 3: Sağlık Çalışanlarının Sanal Kaytarma ve Örgütsel Adalet Algısı Düzeyleri ve ílişkisi

\begin{tabular}{|l|l|c|c|c|c|c|c|c|}
\hline & \multirow{2}{*}{} & \multirow{2}{*}{ Ort. } & \multirow{2}{*}{ Std. S. } & & \multicolumn{5}{|c|}{ Korelasyonlar } \\
\cline { 5 - 9 } & & & & $\mathbf{1}$ & $\mathbf{2}$ & $\mathbf{3}$ & $\mathbf{4}$ & $\mathbf{5}$ \\
\hline 1 & Önemli sanal kaytarma & 2.73 & 0.61 & $\mathbf{( 0 . 7 4 1 )}$ & & & & \\
\hline 2 & Önemsiz sanal kaytarma & 2.59 & 0.84 & $.623^{* *}$ & $\mathbf{( 0 , 7 9 8 )}$ & & & \\
\hline 3 & Dağıtımsal Adalet & 2.53 & 0.71 & -.021 & .042 & $\mathbf{( 0 . 7 6 8 )}$ & & \\
\hline 4 & İşlemsel Adalet & 3.00 & 0.88 & .023 & $-0.174^{* *}$ & $.245^{* *}$ & $\mathbf{( 0 . 8 6 6 )}$ & \\
\hline 5 & Etkileşimsel Adalet & 3.08 & 0.83 & .099 &, 037 & $.275^{* *}$ & $.582^{* *}$ & $\mathbf{( 0 . 9 3 6 )}$ \\
\hline
\end{tabular}

$*_{p}<0.01, \mathrm{~N}=233$, parantez içindeki değerler $\alpha=$ Cronbach alfa güvenilirlik değerini göstermektedir.

Sağlık çalışanlarının önemli ve önemsiz sanal kaytarma düzeylerinin orta düzeyde olduğu görülmektedir. Bununla birlikte katımcıların önemli sanal kaytarma ( $\overline{\mathrm{X}}=2.73)$ düzeyleri önemsiz sanal kaytarma ( $\overline{\mathrm{X}}=2.59)$ düzeyinden daha yüksek bulunmuştur. Benzer bir şekilde katılımcıların örgütsel adalet boyutlarının da orta düzeyde (etkileşimsel ( $\overline{\bar{X}}=3.08)$, işlemsel $(\overline{\bar{X}}=3.00)$ ve dağıtımsal adalet $(\overline{\bar{X}}=2.53))$ olduğu saptanmıştır. Sanal kaytarma ve örgütsel adalet boyutları arasındaki ilişki incelendiğinde, önemsiz sanal kaytarma ile işlemsel adalet $(r=-0,174)$, arasında negatif ve anlamlı düşük oranda korelasyon bulunmuştur.

Tablo 4: Örgütsel Adaletin Önemli Sanal Kaytarma Üzerine Etkisi

\begin{tabular}{|c|c|c|c|c|c|c|c|}
\hline \multirow{2}{*}{$\begin{array}{c}\text { Model I } \\
\text { Bağımsız } \\
\text { Değişkenler }\end{array}$} & \multicolumn{2}{|c|}{$\begin{array}{c}\text { Standardize Edilmemiş } \\
\text { Katsayılar }\end{array}$} & \multirow{2}{*}{$\begin{array}{c}\begin{array}{c}\text { Standardize } \\
\text { edilmiş }\end{array} \\
\text { Beta }\end{array}$} & \multirow[t]{2}{*}{ t değeri } & \multirow{2}{*}{$\begin{array}{l}\text { Anlam } \\
\text { Düzeyi }\end{array}$} & \multicolumn{2}{|c|}{ İç İlişki İstatistikleri } \\
\hline & B & $\begin{array}{l}\text { Standart } \\
\text { Hata }\end{array}$ & & & & $\begin{array}{l}\text { Tolerans } \\
\text { Değeri }\end{array}$ & $\begin{array}{c}\text { VIF } \\
\text { değeri }\end{array}$ \\
\hline Sabit & 21.004 & 1.542 & & 13.621 & .000 & & \\
\hline $\begin{array}{l}\text { 1.Dağıtımsal } \\
\text { Adalet }\end{array}$ & -.066 & .094 & -.048 & -.698 & .486 & .913 & 1.095 \\
\hline
\end{tabular}




\begin{tabular}{|c|c|c|c|c|c|c|c|}
\hline 2. İslemsel Adalet & -.064 & .112 & -.046 & -.571 & .569 & .654 & 1.530 \\
\hline $\begin{array}{l}\text { 3.Etkileşimsel } \\
\text { Adalet }\end{array}$ & .090 & .053 & .139 & 1.695 & .091 & .643 & 1.556 \\
\hline $\mathrm{R}$ & \multicolumn{7}{|c|}{.117} \\
\hline$R^{2}$ & \multicolumn{7}{|c|}{.014} \\
\hline Düzeltilmiş $\mathrm{R}^{2}$ & \multicolumn{7}{|c|}{.001} \\
\hline $\begin{array}{l}\text { Tahmini standart } \\
\text { hata2 }\end{array}$ & \multicolumn{7}{|c|}{4.88380} \\
\hline$F_{(3-233)}$ & \multicolumn{7}{|c|}{1.056} \\
\hline Anlam düzeyi & \multicolumn{7}{|c|}{.369} \\
\hline Durbin-Watson & \multicolumn{7}{|c|}{1.319} \\
\hline
\end{tabular}

Bağımsız değişkenler olan örgütsel adalet boyutlarının bağımlı değişken olan önemli sanal kaytarma üzerinde etkilerinin çoklu regresyon analizi yardımıyla test edildiği görülmektedir (Tablo 4) VIF değerleri 1.095 ila 1.556 arasında değişmekte ve bu değerler en üst sınır olan 10'dan çok düşüktür. En düşük tolerans değeri 0.643 olup, en alt sınır değer olan $0.10^{\prime}$ dan yüksektir. Bu yüzden çoklu bağıntı sorunu ile karşılaşıımamıştır. Ayrıca Durbin-Watson katsayısı 1,319 olduğundan ve bu değer 2'den düşük olduğundan oto korelasyon sorununa rastlanmamıştır. Regresyon analizi bulguları istatistiksel açıdan anlamlı değildir $\left(R^{2}=0.014 ; F_{(3-233)}=1.056 ; p>0.05\right)$.

Bu modelde bağımsız değişken olarak örgütsel adalet boyutlarının önemli sanal kaytarmaya ilişkin varyansın \%1'ini açıklamaktadır. Modelin bulguları incelendiğinde örgütsel adalet boyutlarından etkileşimsel adaletin $(\beta=-0.139 ; p>0.05)$ önemli sanal kaytarma üzerinde pozitif ve anlamlı olmayan bir etkiye sahip olduğu tespit edilmiştir. Dolayısıyla H1c hipotezleri ret edilmiştir. Öte yandan dağıtımsal $(\beta=-0,048 ; p>0.05)$ ve işlemsel adaletin $(\beta=-0.046 ; p>0.05)$ önemli sanal kaytarma üzerinde negatif ama anlamlı olmayan bir etkiye sahip olduğu gözlenmiştir. Bu bulgulara göre $\mathrm{H} 1 \mathrm{a}$ ve $\mathrm{H} 1 \mathrm{~b}$ hipotezleri de desteklenmemektedir.

Tablo 5: Örgütsel Adaletin Önemsiz Sanal Kaytarma Üzerine Etkisi

\begin{tabular}{|c|c|c|c|c|c|c|c|}
\hline \multirow{2}{*}{$\begin{array}{c}\text { Model II } \\
\text { Bağımsız Değişkenler }\end{array}$} & \multicolumn{2}{|c|}{$\begin{array}{c}\text { Standardize Edilmemiş } \\
\text { Katsayılar }\end{array}$} & \multirow{2}{*}{$\begin{array}{c}\text { Standardize } \\
\text { edilmiş } \\
\text { Beta }\end{array}$} & \multirow{2}{*}{ t değeri } & \multirow{2}{*}{$\begin{array}{l}\text { Anlam } \\
\text { Düzeyi }\end{array}$} & \multicolumn{2}{|c|}{ İç iliş̧ki İstatistikleri } \\
\hline & B & $\begin{array}{c}\text { Standart } \\
\text { Hata }\end{array}$ & & & & $\begin{array}{c}\text { Tolerans } \\
\text { Değeri }\end{array}$ & VIF değeri \\
\hline Sabit & 15.999 & 1.555 & & 10.286 & .000 & & \\
\hline 1.Dağıtımsal Adalet & .089 & .095 & .062 & .930 & .353 & .913 & 1.095 \\
\hline 2. İslemsel Adalet & -.432 & .113 & -.303 & -3.833 & .000 & .654 & 1.530 \\
\hline 3.EtkileşimselAdalet & .131 & .053 & .196 & 2.457 & .015 & .643 & 1.556 \\
\hline $\mathrm{R}$ & & & & .250 & & & \\
\hline $\mathrm{R}^{2}$ & & & & .063 & & & \\
\hline Düzeltilmiş $\mathrm{R}^{2}$ & & & & .050 & & & \\
\hline Tahmini standart hata2 & & & & 492634 & & & \\
\hline$F_{(3-233)}$ & & & & 5096 & & & \\
\hline Anlam düzeyi & & & & .002 & & & \\
\hline Durbin-Watson & & & & 1.428 & & & \\
\hline
\end{tabular}

Bağımsız değişkenler olan örgütsel adalet boyutlarının bağımlı değişken olan önemsiz sanal kaytarma üzerinde etkilerinin çoklu regresyon analizi yardımıyla test edildiği görülmektedir (Tablo5) VIF değerleri 1.095 ila 1.556 arasında değişmekte ve bu değerler en üst sınır olan $10^{\prime}$ dan çok düşüktür. En düşük tolerans değeri 0.643 olup, en alt sınır değer olan $0.10^{\prime}$ dan yüksektir. Bu yüzden çoklu bağıntı sorunu ile karşılaşılmamıştır. Durbin-Watson katsayısı 1.428 olduğundan ve bu değer 2 'den düşük olduğundan otokorelasyon sorununa rastlanmamıştır. Regresyon analizi bulguları istatistiksel açıdan anlamlıdır $\left(R^{2}=0.063 ; F_{(3-233)}=5.096 ; p<0.05\right)$.

Bu modelde bağımsız değişken olarak örgütsel adalet boyutlarının önemsiz sanal kaytarmaya ilişkin varyansın \%6'sını açıklamaktadır. Modelin bulguları incelendiğinde örgütsel adalet boyutlarından etkileşimsel adaletin $(\beta=0.196 ; p<0.05)$ beklenilenin aksine önemsiz sanal kaytarma üzerinde pozitif ve anlamlı bir etkiye sahip olduğu saptanmıştır. Dolayısıyla H2c hipotezi ret edilmiştir. Diğer taraftan işlemsel adaletin $(\beta=-0.303 ; p<0.001)$ önemsiz sanal kaytarma üzerinde negatif ve 
anlamlı bir etkiye sahip olduğu saptanmıştır. Dağıtımsal adaletin ise $(\beta=0.062 ; p>0.05)$ önemsiz sanal kaytarma üzerinde pozitif ama anlamlı olmayan bir etkiye sahip olduğu gözlenmiştir. Dolayısıyla H2b hipotezi kabul edilirken, $\mathrm{H} 2 \mathrm{a}$ hipotezi reddedilmektedir.

Tablo 6: Örgütsel Adaletin Sanal Kaytarma Üzerindeki Etkileri

\begin{tabular}{|c|c|c|c|c|c|}
\hline \multirow[t]{2}{*}{$\begin{array}{l}\text { Model III } \\
\text { Bağımsız Değişkenler }\end{array}$} & \multicolumn{2}{|c|}{$\begin{array}{c}\text { Standardize Edilmemiş } \\
\text { Katsayılar }\end{array}$} & \multirow{2}{*}{$\begin{array}{c}\begin{array}{c}\text { Standardize } \\
\text { edilmiş }\end{array} \\
\text { Beta }\end{array}$} & \multirow[t]{2}{*}{ t değeri } & \multirow[t]{2}{*}{$\begin{array}{l}\text { Anlam } \\
\text { Düzeyi }\end{array}$} \\
\hline & B & Standart Hata & & & \\
\hline Sabit & 36.431 & 2.729 & & 13.351 & .000 \\
\hline Örgütsel Adalet & .020 & .051 & .026 & .394 & .694 \\
\hline $\mathrm{R}$ & \multicolumn{5}{|c|}{.026} \\
\hline $\mathrm{R}^{2}$ & \multicolumn{5}{|c|}{.001} \\
\hline Düzeltilmiş $\mathrm{R}^{2}$ & \multicolumn{5}{|c|}{-.004} \\
\hline Tahmini standart hata & \multicolumn{5}{|c|}{8.97077} \\
\hline$F_{(1-233)}$ & \multicolumn{5}{|c|}{.155} \\
\hline Anlam düzeyi & \multicolumn{5}{|c|}{.694} \\
\hline
\end{tabular}

$* p<0.05 . \quad * * p<0.01 ;$ Bağımlı Değişken: Sanal Kaytarma

Örgütsel adaletin bağımsız değişken, sanal kaytarmanın bağımlı değişken olduğu Model III basit regresyon analizi ile test edilmiştir (Tablo 6). Basit regresyon analizi bulgularına göre Model III istatistiksel açıdan anlamlı değildir $\left(R^{2}=.001 ; F_{(1-233)}=\right.$ 0.155 p >0.05). Bu modelde bağımsız değişken örgütsel adaletin sanal kaytarmadaki varyansın \%0,01'ini açıklamaktadır. Basit regresyon analizi sonuçları incelendiğinde örgütsel adaletin sanal kaytarma üzerinde pozitif ancak anlamlı bir etkiye sahip olmadığı tespit edilmiştir ( $\beta=0.026 ; p>0.05)$ Söz konusu bulgular dikkate alındığında H3 hipotezi ret edilmiştir.

\section{TARTIŞMA}

Bu bölümde araştırma kapsamında elde edilen bulguları ile ilişkili çalışmalar yer almaktadır. Çalışmamız sonuçları doğrultusunda diğer çalışmaların bulgularına ilişkili bir şekilde yer verilmiştir.

Sanal kaytarma kurumlar için son derece zararlı olabilir ve verimlilik kayıplarına neden olabilir. Ancak, sanal kaytarmanın kişisel gelişim fırsatlarına, üretkenlik artışına ve eşsiz öğrenme fırsatlarına vurgu yapılarak faydalı yanlarının da olabileceği belirtilmiştir (Keklik vd., 2015). Kim ve Byrne (2011) sanal kaytarmanın kısmen de olsa öz-kontrol eksikliği ile ilgili olduğunu belirtmiştir. Blanchard ve Henle (2008), sanal kaytarmayı önemli ve önemsiz sanal kaytarma olarak ikiye ayırmıştır. Önemli sanal kaytarmada çalışanlar, kullandıkları sitelerin kendileri için ne kadar tehlikeli olduklarını ve bunun getireceği kanuni yükümlülükleri de bilseler bile kaytarma aktivitelerinde bulunmaya devam etmektedirler (Yıldız ve ark., 2015). Önemsiz sanal kaytarmada e-mail teknolojisinin ve internetin yaygın bir biçimde kullanım alanları sıralanmaktadır. Örneğin, e-mail almak veya göndermek, haber kanallarına girip haber indirmek, spor ve finans sitelerine girmek ve bunları okumak gibi aktivitelerdir (Blanchard ve Henle, 2008). Ancak bu davranışlar örgütün verimliliğini etkileyebileceğinden tamamen tolere edilebilecek iş davranışları değildir (Özkalp ve ark., 2012). Önemsiz sanal kaytarma eylemlerinde bulunan çalışanlar bu kaytarmayı olağan bir durum olarak karşılamakta ve bu kaytarmanın işletme kaynaklarına zarar vermediğini düşündükleri ifade edilmektedir (Örücü ve Yıldız, 2014). Lim ve Chen (2012) araştırmalarında internette sörf yapma aktivitelerinin çalışanların duygularını pozitif olarak etkilediği, çalışanın zihnini canlandırdığı ve böylece çalışanın üretkenliğine katkıda bulunduğunu saptamışlardır. İnce ve Gül (2011) araştırmalarında içsel kontrol odağına sahip olan çalışanların önemsiz sanal kaytarma davranışlarının, iş performansını artırdığı ve bu şekilde çalışanların işten ayrılma niyetlerinin azaldığını saptamışlardır. Çalışmamızda sağlık çalışanlarının sanal kaytarma düzeyleri incelendiğinde katılımcıların önemli sanal kaytarma $(\overline{\bar{X}}=2,73)$ düzeyleri önemsiz sanal kaytarma $(\overline{\bar{X}}=2,59)$ düzeyinden daha yüksek bulunmuştur. Bununla birlikte önemli ve önemsiz sanal kaytarma düzeyleri orta düzeydedir. Ayrıca örgütsel adalet düzeyleri de orta düzeyde olduğu saptanmıştır. Sanal kaytarma ve örgütsel adalet boyutları arasındaki ilişkiler incelendiğinde, sadece önemsiz sanal kaytarma ile işlemsel adalet arasında negatif ve anlamlı düşük oranda ilişki bulunmuştur.

Örgütsel adalet algılamaları ile sanal kaytarma faaliyetleri arasındaki ilişkiyi inceleyen araştırmalar, ağırlıklı olarak örgütsel adalet ile sanal kaytarma arasında negatif yönlü bir ilişki olduğunu ortaya koymaktadır (Lim, 2002; Ahmadi ve ark, 2011). Yani örgütsel adalet algısı azaldıkça, çalışanların sanal kaytarma faaliyetleri artmaktadır. Bu noktadan hareketle örgütsel adalet algısı ile sanal kaytarma arasında negatif bir ilişki bulunduğu düşünülmektedir. Kaplan ve Ögüt (2012) araştırmalarında dağıtım, işlemsel ve etkileşim adalet ile önemsiz sanal kaytarma arasında negatif ilişki saptamıştır. Yıldız arkadaşları (2015), araştırmalarında örgütsel adalet algısının tüm boyutları ile önemli ve önemsiz sanal kaytarma davranışları arasında ilişki saptayamamışlardır. Zoghbi-Manrique-de-Lara (2007) çalışmasında işlemsel ve etkileşimsel adalet 
ile sanal kaytarma arasında ilişki belirleyemezken, dağıtımsal adalet ile sanal kaytarma arasında pozitif bir ilişki saptamıştır. Çalışmamızda regresyon analizi bulgularına göre genel olarak örgütsel adaletin sanal kaytarma üzerinde anlamlı bir etkisi saptanmamıştır. Ayrıca önemli sanal kaytarma değişkenini etkileyen örgütsel adalet alt boyutları bulunamamıştır. Örgütsel adalet boyutlarından etkileşimsel adaletin önemli sanal kaytarma üzerinde pozitif ve anlamlı olmayan bir etkiye sahip olduğu tespit edilmiştir. Öte yandan dağıtımsal ve işlemsel adaletin önemli sanal kaytarma üzerinde negatif ama anlamlı olmayan bir etkiye sahip olduğu gözlenmiştir. Bu bulgulara göre örgütsel adalet boyutlarının önemli sanal kaytarma

Örgütsel adalet boyutlarından dağıtım adaleti, bireyin sosyal etkileşim ve değişimden algıladığı adaleti ifade etmektedir. Bireyler kendi girdilerini çıktıları ile karşılaştırıllar ve çıktıların adil olup olmadığını başkalarının oranlarıyla ya da standartlarla karşılaştırırlar (Nowkowski ve Conlon, 2005). Eşitlik teorisi içerisinde yer alan dağıtım adaleti ilkesine göre ilgili açılardan benzer olan bireylere benzer davranılmalı, farklı olan bireylere ise, onlar arasındaki farklar oranında farklı davranılmalıdır. Bu teorinin özü, eşit çabanın eşit sonuç getirmesi gerekliliğidir. Bir yönetici yaş, cinsiyet, din veya ırk gibi subjektif özelliklere dayalı olarak terfi ya da ödülleri dağıtmamalı ve bunun gibi olgulara dayanan sübjektif kararlar yüzünden sistematik olarak insanlara karşı ayrımcılığın olmamasını temin etmelidir (İşan ve Sayın, 2010). Yapılan bir çalışmada dağıtım adaletinin önemli ve önemsiz sanal kaytarmayı negatif etkilediği belirlenmiştir (Kaplan ve Öğüt 2012). Çalışmamızda dağıtımsal adaletin önemsiz sanal kaytarma üzerinde pozitif ama anlamlı olmayan bir etkiye sahip olduğu gözlenmiştir. Dolayısıyla H2a hipotezi reddedilmiştir.

Örgütsel adalet boyutlarından biri olan işlemsel adalet, örgütlerde fazla veya az ödemelerden kaçınma, kurumda alınan kararlara katılım, sonuçlarla ilgili bilgi verme gibi örgütsel uygulamaların işgörenler arasında eşit yapılması olarak tanımlanabilir (Colquıtt ve Chertkoff, 2002). Kural ve yöntemlerin hakkaniyetine dönük adalet algılaması olan işlemsel adalet kazanımların belirlenmesi sürecinde kullanılmaktadır. İşlemsel adalet; kararlarda tutarlılık, önyargıdan uzaklık, doğru bilgiye dayalı kararlar, yanlış kararları düzeltme yeteneği, geçerli kurallara uyum ve kararlardan etkilenen kişilerin görüşlerinin alınması konularını kapsamaktadır (Kaplan ve Öğüt, 2012). İşlemsel adaleti uygulayan yöneticiler, yönetsel kararlardan etkilenen insanların karar verme sürecine onaylarından ve sürecin tarafsız olarak uygulandığından emin olurlar. Onay, insanların bilgilendirildikleri ve var olan sistemi seçme özgürlüğüne sahip oldukları anlamına gelir (İşcan ve Sayın, 2010). Çalışmamızda işlemsel adaletin önemsiz sanal kaytarma üzerinde negatif ve anlamlı bir etkiye sahip olduğu saptanmıştır. Dolayısıyla H2b hipotezi kabul edilmiştir. Başka bir ifadeyle, işlemsel adalet algılaması olumsuz olduğunda önemsiz sanal kaytarma davranışı artmaktadır. Buna göre kararlara katılım ve bilgi verme olumsuz algılandığında önemsiz sanal kaytarma davranışını arttırdığı söylenebilir.

Örgütsel adaletin üçüncü boyutu olan etkileşimsel adalet ise, kural ve prosedürlerin işleyişi sırasında bireylere yapılan muamelelerin niteliği olarak tanımlanmaktadır. Etkileşimsel adaletin sağlanması için yöneticiler karar verme süreçlerinde işgörenlere karşı önyargılı yaklaşımlardan kaçınmalı, dürüst, açık, saygılı olmalı, süreçler hakkında çalışanlara gerekli açıklamaları samimi bir şekilde yapmalıdırlar (Bies, 1986; Kaplan ve Öğüt, 2012). Diğer bir ifadeyle etkileşimsel adalet yöneticilerin işgörene davranışlarını açıklamaya çalışan bir adalet biçimi olarak açıklanmaktadır (Yavuz, 2010). Çalışmamızda örgütsel adalet boyutlarından etkileşimsel adaletin beklenilenin aksine önemsiz sanal kaytarma üzerinde pozitif ve anlamlı bir etkiye sahip olduğu saptanmıştır. Dolayısıyla H2c hipotezi reddedilmiştir. Başka bir ifadeyle, etkileşimsel adalet algılaması olumlu algılandığında önemsiz sanal kaytarma davranışı artmaktadır. Buna göre bireylere yönelik muamelenin kalitesi olumlu algılandığında önemsiz sanal kaytarma davranışı arttığı söylenebilir.

\section{SONUÇ VE ÖNERILER}

Bu araştırmada sağıık çalışanlarının sanal kaytarma davranışlarının örgütsel adaletten ne derece etkilendiği ve aralarındaki ilişki araştırılmıştır.

Araştırma bulgularına göre, örgütsel adalet algılamasının olumlu veya olumsuz olarak algılanması önemli sanal kaytarma davranışlarında artış veya azalışa neden olmamaktadır. Önemli sanal kaytarma davranışlarının azaltılması bir kurum için daha önemli olacağı için, örgütsel adalet algılamasının önemli sanal kaytarmayı etkilememesi iyi bir sonuçtur. Önemsiz sanal kaytarma bulguları incelendiğinde ise, çalışanlar etkileşimsel adaleti olumlu algıladıklarında, bireylere yönelik muamelenin kalitesi arttı̆̆ından yöneticiden çekinmeden önemsiz sanal kaytarma davranışları göstermektedirler. Ayrıca, işlemsel adalet çalışanlar tarafından adil olarak algılanmadığında ya da kurumda alınan kararlara katıım ve sonuçlarla ilgili bilgi verme gibi örgütsel uygulamaların işgörenler arasında eşit yapılmadığı algılandığında, önemsiz sanal kaytarma davranışlarında artış görülmektedir. Buna göre çalışanlar tarafından önemsiz sanal kaytarma davranışlarını olağan bir durum olarak karşılamakta olduğunu ve bu durum örgüte zarar verici olmadığını, bireysel olarak kendilerinin gelişiminde katkı sağladığını ve iş performansına olumlu etki sağladığını düşünmelerinden kaynaklandığını söyleyebiliriz.

Sonuç olarak çalışanlar işini en iyi şekilde yapıyorsa, işinde bir aksaklığa neden olmuyorsa; örgütün amaçlarını gerçekleştirmede ve çalışanların bireysel gelişimlerinde katkısı olabilecek konularla sınırlı olmak koşuluyla; web kullanım süresinin sınırlı olması koşuluyla; iş molalarında veya işlerini tamamlamaları halinde kalan boş zamanı kullanmaları durumlarında ve sanal kaytarma önemli düzeye geçmediği sürece; çalışanların önemsiz sanal kaytarma davranışlarına 
örgütün çok katı olmaması önerilebilir. Bu durum çalışanların motivasyonlarına ve bireysel kariyerlerine olumlu etkisi olabilir. Ayrıca hızla değişen bir dünyada değişiklikleri ve teknolojiyi takip etmemek, iletişim kurmamak veya mesai saatinin bitmesini beklemeden kişisel e-postalara bakmak gibi, önemsiz sanal kaytarma durumları çalışanların körelmesine neden olabilir. Bu durum örgütün gelişmesini de olumsuz etkileyebilir. Bunun yanı sıra örneğin internet üzerinden bankacılık işlemlerini yapmalarına izin vermemek kişinin örgütten izin alıp bankaya gitmesine neden olacaktır. İzin süresiyle kaybedilecek zaman ve zarar düşünüldüğünde bazı önemsiz sanal kaytarma davranışlarına izin vermek örgüte yararı dahi olabilir.

\section{KAYNAKLAR}

Ahmadi, H., Bagheri, F., Ebrahimi, SA., Rokni, MAN., Kahreh, MS. 2011, "Deviant Work Behavior: Explaining Relationship between Organizational Justice and Cyber-Loafing as a Deviant Work Behavior", American Journal of Scientific Research, 24,pp.103-116.

Blanchard, A. L. \& Henle, CA. 2008, "Correlates of Different Forms of Cyberloafing: The Role of Norms and External Locus of Control", Computers in Human Behavior, vol.24, no.3, pp. 1067-1084.

Bies, R.J., Moag, J.S. 1986, "Interactional justice: Commu-nication criteria of fairness". In R. J. Lewicki, B H. Sheppard, \& M. H. Bazerman (Eds.), Research on negotiation in organizations,, pp. 43-55.

Colquitt, J. A., \& Chertkoff, J. M. 2002, “Explaining injustice: The Interactive Effect of Explanation and Outcome on Fairness Perceptions and Task Motivation", Journal of Management, vol.28, no. 5, pp. 591-610.

Cropanzano R. and Greenberg J. 1997, Chapter to appear in C. L. Cooper \& I. T. Robertson (Eds.). Iptematjonal Review of Industrial and Orpnizational Psychology. New York: John Wiley \& Sons.

Eivazi, K. 2011, "Computer Use Monitoring and Privacy at Work", Computer Law \& Security Review, vol.27, no.5, pp. 516-523.

Forret, M. \& Love, M. S. 2008, “Employee Justice Perception and Coworker Relationship". Leaderships \& Organization Development, vol.29, no. 3, pp.248-260.

Greenberg, J. 1990, “Organizational justice: Yesterday, today, and tomorrow”, Journal of management, vol.16, no. 2, pp.399-432.

Ince, M. \& Gül, H. 2011, "The Relation of Cyber Slacking Behaviors with Various Organizational Outputs: Example of Karamanoğlu Mehmetbey University", European Journal of Scientific Research, vol. 52, , no. 4, pp.507-527.

İşcan, Ö. F. \& Sayın, U. 2010, "Örgütsel Adalet, İ̧̧ Tatmini ve Örgütsel Güven Arasındaki İlişki”, Atatürk Üniversitesi Iktisadi ve Idari Bilimler Dergisi, vol.24, , no. 4, pp. 195-216.

Kaplan M. \& Çetinkaya A.Ş 2014, "Sanal Kaytarma ve Demografik Özellikler Açısından Farklılıklar: Otel İşletmelerinde Bir Araştırma", Anatolia: Turizm Araştırmaları Dergisi, vol.25, no. 1, pp.26 - 34

Kaplan, M. \& Öğüt, A. 2012, "Algılanan Örgütsel Adalet İle Sanal Kaytarma Arasındaki İlişkinin Analizi: Hastane Çalışanları Örneği", işsletme Fakültesi Dergisi, vol.13, no. 1, pp. 1-13.

Keklik, B., Kılıç, R., Yıldız, H., \& Yıldız, B. 2015, "Sanal Kaytarma Davranışlarının Örgütsel Öğrenme Kapasitesi Üzerindeki Etkisinin Incelenmesi/An Investigation of the Effect of Cyberloafing Behaviors on Organizational Learning Capacity", Business and Economics Research Journal, vol.6, no. 3, pp. 129-144.

Kim, S. J. \& Byrne, S. 2011, "Conceptualizing Personal Web Usage in Work Contexts: A Preliminary Framework", Computers in Human Behavior, vol.27, no. 6, pp. 2271-2283.

Lim, V. K. G. 2002, "The IT Way of Loafing on the Job: Cyberloafing, Neutralizing and Organizational Justice", Journal of Organizational Behavior, 23, pp. 675-694.

Lim, V. K., \& Chen, D. J. 2012, “Cyberloafing at the workplace: gain or drain on work?”, Behaviour \& Information Technology, vol.31, no. 4, pp. 343-353.

Nowakowski, J,M . \& Conlon D, E. 2005, "Organizational Justice: Looking Back, Looking Forward”, The International Journal of Conflict Management, vol.16, no.1, pp. 4-29.

Niehoff, B.P. \& Moorman, R.H. 1993, “Justice As a Mediator of the Relationship between Methods of Monitoring and Organizational Citizenship Behavior", Academy of Management Journal, vol. 36, no.3, pp. 527-556.

Örücü, E. \& Yıldız, H. 2014, “İşyerinde Kişisel İnternet ve Teknoloji Kullanımı: Sanal Kaytarma”, Ege Akademik Bakış, vol.14, no.1, pp. 99-114.

Özkalp, E., Aydın, U. \& Tekeli, S. 2012, “Sapkın Örgütsel Davranışlar ve Çalışma Yaşamında Yeni Bir Olgu: Sanal Kaytarma (Cyberloafing) ve İ̧̧ İlişkilerine Etkileri", Çimento İşveren Sendikası Dergisi, vol.26, no.2, pp. 18-33.

Richardson, K. \& Benbunan-Fich, R. 2011, "Examining the Antecedents of Work Connectivity Behavior during No-Work Time", Information and Organization, vol.21, no.3, pp. 142-160. 
Syaebani, M. I. \& Sobri, R. R. 2011, "Relationship between Organizational Justice Perception and Engagement in Deviant Workplace Behavior", The South East Asian Journal Management, vol. 5, no. 1, pp.37-49.

Weatherbee, T. G. 2010, "Counterproductive Use of Technology at Work: Information \& Communications Technologies and Cyberdeviancy", Human Resource Management Review, vol.20, no. 1, pp.35-44.

Whitty, M. T. \& Carr, A. N. 2006, "New Rules in the Workplace: Applying Object-Relations Theory to Explain Problem Internet and Email Behavior in the Workplace", Computers in Human Behavior, vol.22, no. 2, pp. 235-250.

Türkiye Istatistik Kurumu (TÜiK). Hane halkı Bilişim Teknolojileri Kullanım Araştırması, http://www.tuik.gov.tr/PreHaberBultenleri.do?id=21779 (Erişim Tarihi, 03 Haziran 2017).

Yavuz, E. 2010, "Kamu ve özel sektör çalışanlarının örgütsel adalet algılamaları üzerine bir karşılaştırma çalışması", Doğuş Üniversitesi Dergisi, vol.11, no.2, pp.302-312.

Yıldız H., Yıldız B. \&Ateş H. 2015, "Sanal Kaytarma Davranışlarının Sergirilmesinde Örgütsel Adalet Algısının Rolü Var mıdır?”, Bilgi, Ekonomi ve Yönetimi Dergisi, vol.X, no.II, pp..55-66.

Zoghbi-Manrique-de-Lara, P. 2007, "Relationship between Organizational Justice and Cyberloafing in the Workplace: Has "Anomia” a Say in the Matter?", CyberPsychology\& Behavior, vol. 10(3), pp. 464-470.

Zoghbi-Manrique-de-Lara, P. \& Melián-González, S. 2009, "The Role of Anomia on the Relationship between Organisational Justice Perceptions and Organisational Citizenship Online Behaviours, Journal of Information", Communication and Ethics in Society , vol.7, no.1, pp. 72-85. 